\title{
3D seismic structure of the Zhenbei-Huangyan seamounts chain in the East Sub-basin of the South China Sea and its mechanism of formation
}

\author{
Wang Jian ${ }^{1,2}$, Zhao Minghui ${ }^{1,{ }^{*}}$, Qiu Xuelin ${ }^{1}$, Sibuet Jean-Claude ${ }^{3,4}$, He Enyuan ${ }^{1,2}$, \\ Zhang Jiazheng ${ }^{1}$, Tao Chunhui ${ }^{5}$
}

${ }^{1}$ Key Laboratory of Marginal Sea Geology, South China Sea Institute of Oceanology; Chinese Academy of Sciences; Guangzhou, China

2 University of Chinese Academy of Sciences; Beijing, China

${ }^{3}$ Ifremer, Centre de Brest; Plouzané ,France

${ }_{5}^{4} 44$ rue du Cloitre; Plouzané, France

${ }^{5}$ The Second Institute of Oceanography, State Oceanic Administration; Hangzhou ,China

* Corresponding author : Minghui Zhao, email address : $\underline{\text { mhzhao@scsio.ac.cn }}$

\begin{abstract}
:
The probable $\mathrm{N} 055^{\circ}$-oriented extinct spreading ridge of the East Sub-basin is cut across by the postspreading volcanic ridge oriented approximately $\mathrm{E}-\mathrm{W}$ in its western part and called the ZhenbeiHuangyan seamounts chain. A three-dimensional ocean bottom seismometer survey was conducted in 2011 and covered both the extinct spreading ridge and the Zhenbei-Huangyan seamounts chain in the East Sub-basin. The comprehensive seismic record sections of 39 ocean bottom seismometers underline the high-quality data with clear and reliable P-wave seismic first arrivals. The threedimensional tomographic results show that the crust is oceanic on each side of the Zhenbei-Huangyan seamounts chain. The seafloor spreading lineaments and associated fracture zones pattern provide channels for magma migration and eruption. Based on the ratio of volcanic extrusive and intrusive materials and the shape of the upward convex $6.4 \mathrm{~km} / \mathrm{s}$ iso-velocity curve beneath the Zhenbei and Huangyan seamounts, we conclude that the Zhenbei and Huangyan seamounts appear to be dominantly formed by intra-crustal intrusion. Combining previous geochemical studies of post-spreading volcanic ridge outcropping samples, the formation mechanism of the seamounts chain might be explained by a buoyancy-driven decompression melting mechanism occurring as separately evolving partial melting bodies beneath each seamount.
\end{abstract}

Keywords : extinct spreading ridge, Zhenbei-Huangyan seamounts chain, 3D seismic structure, postspreading magmatism, East Sub-basin, South China Sea 


\section{Introduction}

Seamounts are an important component of the oceanic lithosphere, texturing the world's ocean basins in linear chains or mountainous provinces (Hammer et al., 1994). The South China Sea (SCS) is a small oceanic basin formed during the Cenozoic seafloor spreading, but is also considered as a marginal sea, which preserves both seafloor spreading and post-spreading volcanic features (Taylor and Hayes, 1983; Briais et al., 1993). The East sub-basin is characterized by a lot of widely distributed seamounts (Fig.1). The approximately E-W Zhenbei-Huangyan seamounts chain is as a post-spreading magmatic chain formed after the cessation of seafloor spreading (Wang et al., 1984; Tu et al., 1992; Briais et al., 1993; Wang et al., 2009; Xu et al., 2012). However, both the age of seafloor spreading cessation and the location of the extinct spreading ridge (ESR) in the East sub-basin are controversial (Sibuet et al., 2015 revised) because the post-spreading magmatic activities mask the spreading fabric especially near the extinct seafloor spreading axis. Thus, the ESR of the East sub-basin is either beneath the Zhenbei-Huangyan seamounts chain (Taylor and Hayes, 1980; Briais et al., 1993; Li et al., 2014; Barckausen et al., 2014) or, based on swath-bathymetric data, is N055 trending (Fig. 1) (Sibuet et al., 2015 revised). Depending of already published ages of the end of seafloor spreading in the East sub-basin 15.5 to 20.5 Ma discrepancies exist (Briais et al., 1993; Li et al., 2014; Expedition 349 Scientists, 2014; Barckhausen et al., 2014; Sibuet et al., 2015 revised). In fact, the reason of such discrepancies is mostly due to the presence of the post-spreading magmatism, which affects the morphology and nature of the crust. What is the nature of the Zhenbei-Huangyan seamounts chain? What is the relationship between the PSVR and the ESR in the East sub-basin? These are critical points to understand the formation and evolution of the SCS.

Despite the abundance of seamounts in the SCS, our knowledge of the seamount structure and their mechanism formation remain limited. Two major mechanisms were proposed. One is the hotspot/mantle plume mechanism (Wilson, 1963), the other one is the buoyancy-driven decompression melting mechanism which explains, for example, the formation of the Davidson Seamount above the fossil spreading center in the eastern Pacific (Castillo et al., 2010).

Deep seismic surveys allow us to understand the crustal characteristics and formation mechanism of the Zhenbei-Huangyan seamounts chain. A three dimensional (3D) Ocean Bottom Seismometer (OBS) seismic survey was designed with three main aims: 1) to investigate the 
nature of the seamounts chain;2) to investigate the velocity structure beneath the seamounts in order to determine their mode of formation; and 3) to provide constrains for the relationship between the ESR and the seamounts chain. In this paper we present a tomographic model established by inversion of the first arrivals recorded by 39 OBSs deployed during this survey.

\section{Geological setting}

The SCS is one of the largest marginal seas in the western Pacific Ocean. It is located at the junction of the Eurasian, India, Australia and Pacific plates and divided geographically into the SW sub-basin, the NW sub-basin and the East sub-basin (Fig.1). It has experienced multiple episodes of spreading and tectonic activities (Taylor and Hayes, 1983; Briais et al., 1993; Li et al., 2014; Sibuet et al., 2015 revised). After the cessation of seafloor spreading, the PSVR was partly built along the $\mathrm{N} 055^{\circ}$ oriented ESR in the eastern part of the East sub-basin (Fig. 1) and partly obliquely across the ESR (E-W trending Zhenbei-Huangyan seamounts chain) in the western part of the East sub-basin (Wang et al., 1984; Tu et al., 1992; Briais et al., 1993; Wang et al., 2009; Sibuet et al., 2015 revised).

From combined analyses of the International Ocean Discovery Program Expedition 349 cores (Li et al., 2015) and deep tow magnetic anomalies (Li et al., 2014; Barckhausen et al., 2014), the onset of seafloor spreading in the central part is dated at 33-32 Ma, corresponding to the age of the oldest identified magnetic anomalies C12 (Briais et al., 1993; Li et al., 2014; Barckhausen et al., 2014). A southward ridge jump of ca. $20 \mathrm{~km}$ occurred around $23.6 \mathrm{Ma}(\mathrm{C} 6 \mathrm{Cr})$ in the East sub-basin (Fig.1) and is coeval to the onset of seafloor spreading in the SW sub-basin. The second spreading phase developed from 23.6 to $21.5 \mathrm{Ma}$ along about $400 \mathrm{~km}$ in a NNE-SSW direction (Li et al., 2014). Preliminary ages of spreading ending is ca. 15 Ma in the East sub-basin and ca. 16 Ma in the SW sub-basin (Leg 349 preliminary report) but may be much older (Sibuet et al., 2015 revised). The most recent oceanic domain in the East sub-basin is located in between the two red dashed lines of Figure 1, which corresponds to the boundaries of the oceanic domain where N055 seafloor spreading lineaments were identified (Sibuet et al., 2015 revised).

Seamounts prevail in the SCS since the onset of post-spreading magmatism (13 Ma, Leg 349 preliminary report). The Zhenbei and Huangyan seamounts chain consists of volcanic edifices nearly $3000-4000 \mathrm{~m}$ above the seafloor and rising from ca. $240 \mathrm{~km}$ in length and $40-60 \mathrm{~km}$ in 
width (Yao, 1996; Yan et al., 2006). Unlike most seamount groups, the Zhenbei and Huangyan seamounts chain does not exhibit a hotspot chain type formation, with increasingly older volcanoes along it (such as Hawaiian seamounts), nor does it runs perpendicularly to a local rift zone. In fact, it intersects the $\mathrm{N} 055^{\circ}$ roughly oriented ESR of the East sub-basin.

\section{Data acquisition, processing and analysis}

In May 2011, the $R / V$ Shiyan 2 carried out a large-scale 3D OBS experiment for the first time in the East sub-basin of SCS (Qiu et al., 2012; Zhang et al., 2013) in cooperation between the South China Sea Institute of the Academy of Sciences, the Second Marine Research Institute of the State Oceanic Administration, Seimological Bureau of Guangdong Province and Guangzhou Marine Geological Survey. The seismic network was centered along the Zhenbei and Huangyan seamounts chain (Fig. 2). 42 OBSs with 3-component geophones and one hydrophone were deployed and recorded air-gun signals (Fig. 2). The OBS pool includes32 OBSs of domestic broadband OBS I-7c type and 10 OBSs of German Sedis IV type. The sampling rates were set up at $125 \mathrm{~Hz}$ and $250 \mathrm{~Hz}$, respectively. The seismic data recorded by the 39 OBSs were effectively used for the processing. The source system was composed of an array of four-air-guns with a total volume of 98.3 liters towed at $10 \mathrm{~m}$ depth below the sea surface. A total of 8252 shots were fired at a $120 \mathrm{~s}$ interval. The shooting length is about $2500 \mathrm{~km}$. The locations of the 39 OBSs on the seafloor were determined by inverting the direct water wave travel-times using the Monte Carlo and least square methods, which yielded error estimates within 10-20 m (Zhang et al., 2013). The water depths at relocated positions were obtained from multi-beam bathymetric measurements.

The seismic data were reduced to the standard SEGY format. Globally, OBS data are of good quality with seismic signals recorded down to the Moho interface. In this study, we concentrate exclusively on $P$-wave first arrivals for each OBS. We manually pick first arrival travel-times in a band-pass filtered $(3-8 \mathrm{~Hz})$. The recorded sections are displayed with a reduced velocity of 6.0 $\mathrm{km} / \mathrm{s}$ for the hydrophone component (sometimes vertical component) without differentiating between crustal and mantle refracted phases $(P g$ and $P n)$ and excluding direct water-wave phases (Fig. 3). In total, we picked 95,430 first arrival travel times from the 39 OBSs' recorded sections. Observed travel-time uncertainties were calculated based on the signal-to-noise ratio (SNR) (e.g., Zelt and Forsyth, 1994). In addition, a constant value of $20 \mathrm{~ms}$ is added to account for uncertainty 
in seafloor ray entry point in areas with obvious topographic changes.

\section{Modeling Results}

\subsection{Tomography Method}

The iterative first-arrival seismic tomography approach (FAST) of Zelt and Barton (1998) was used to construct a smooth, isotropic 3D $P$-wave velocity model beneath the Zhenbei-Huangyan seamounts chain. The one-dimensional (1D) velocity model is firstly built in order to construct the initial 3D volume. The seafloor interface was taken from multi-beam bathymetric data previously acquired. The velocity was set up to $1.5 \mathrm{~km} / \mathrm{s}$ for the water layer. We tried to get a solution with the least amount of required structure that adequately fits the observed travel-times (low RMS and $\chi^{2}$ close to 1 ideally) in the least number of iterations. This is accomplished by normalizing all regularized operators by the slowness of the starting model, linearizing by damped least squares solution (LSQR) (Zelt and Barton, 1998). Lambda, a trade-off parameter, controls the relative weighting of fitting the travel-time data vs. solution constraints, and the parameter Alpha controls the relative importance of smoothness/flatness vs. smallest perturbation within the regularization part. We run a number of inversions to find the appropriate Lambda value as well as the appropriate value $\left(D_{x y}\right)$ of the horizontal grid node spacing for the inverse problem. The forward problem (ray path and travel time calculations) is solved on this 3D volume parameterized with a uniform square node spacing of $500 \mathrm{~m}$ in $\mathrm{X}, \mathrm{Y}$, and $\mathrm{Z}$ directions. A relatively dense parameterization of $329 \times 239$ horizontal nodes in an area of $164 \mathrm{~km} \times 119 \mathrm{~km}$ and 51 vertical nodes from 0 to $25 \mathrm{~km}$ below the seafloor is used $(4,010,181$ spacing nodes in total arranged in a regular grid). The inverse problem uses a volume with a 1000-m cell spacing in the two horizontal directions $(164 \times 119$ cells) and in the vertical direction (25) (487900 cells in total). Travel-times calculated from this 3D structure poorly fit the data $\left(\chi^{2}>30\right.$; Fig. 4a) with residuals ranging between -2000 to $800 \mathrm{~ms}$, and larger positive (blue) and negative (red) residuals in the first inversion (Fig. 4b). After four iterations, the results show that the combination of Lamda=2, $D_{x y}=500 \mathrm{~m}$, and $s_{z}=1$ provides the best fit to the data with a RMS misfit of $53 \mathrm{~ms}$ and a corresponding normalized misfit $\chi^{2}=1.54$ (Fig. 4c) (Wang et al., 2014). All instruments and shots are equally well fit (i.e., travel-time residuals do not show dependence on shot number or OBS number, Fig. 4d). The travel-time residuals are independent to source-receiver offsets, indicating 
that observed data equally fit well at all offsets (Fig. 4e).

\subsection{Preferred $P$-Wave Velocity Model}

Any solution to the inverse problem depends on the starting model chosen to a certain degree, and a complete solution must include a measurement of uncertainty. We followed a Monte Carlo approach similar to that of Zhang et al. (1998) and Korenaga et al. (2000) in order to account for the influence of the starting model on the solution and to obtain an estimate of the uncertainty. One hundred 1D starting models were constructed by randomizing five parameters defining a two-layer media: $P$-wave velocities at the top of the upper layer (seafloor), at the interface between both layers, and at the bottom of the lower layer, and the thicknesses of both layers. These five parameters avoid constructing unrealistic models (Fig. 5). The velocities at the seafloor, middle interface, and at the bottom of the model were limited to $2-4 \mathrm{~km} / \mathrm{s}, 5.3-7.3 \mathrm{~km} / \mathrm{s}$ and $7.3-8.5 \mathrm{~km} / \mathrm{s}$, respectively. The thicknesses of both layers were limited to be within $1-3 \mathrm{~km}$ and 7-22 km for the upper and lower layers, respectively. For each Monte Carlo ensemble, a 3D starting model was constructed by draping the randomized $1 \mathrm{D}$ velocity model from the seafloor bathymetry. The 100 different inversions were performed using the same parameters. Assuming that the random initial models are independent of each other and that all solutions are equally valid, the average ensemble and the standard deviation of the 100 solutions are valid statistical estimates of the final model and its uncertainty (e.g., Korenaga et al., 2000). The average model of the final ensemble (preferred solution) is our preferred velocity model (Fig. 5). The 3D image of $P$-wave velocity in the $164 \mathrm{~km} \times 119 \mathrm{~km} \times 25 \mathrm{~km}$ volume shows the seismic structure centered on the Zhenbei-Huangyan seamounts chain.

Checkerboard tests are commonly used for model assessment and resolution analysis. They provide information on the lateral and vertical resolution of a velocity model by examining the ability to recover the velocity anomaly pattern superimposed on the velocity model (Zelt, 1998). A perturbed velocity model was built by superimposing a 3D sinusoidal velocity anomaly on the best fitting model with the magnitude of $10 \%$ of the background velocity. The sinusoidal function has half-wavelengths of $8 \mathrm{~km}$ in the horizontal directions and $3.5 \mathrm{~km}$ in the vertical direction (Fig. 6). Synthetic travel times were generated by tracing rays through the perturbed velocity models and then by adding Gaussian random noise with a standard deviation of $15 \mathrm{~ms}$. These synthetic 
travel-time data were then inverted for the preferred velocity model as the starting model using the same parameters as the previous inversion. We find that the inversion is able to resolve the checkerboard pattern (Fig. 6). A good recovery of the velocity perturbation is observed with velocity anomaly of size $8 \times 8 \times 3.5 \mathrm{~km}$, indicating a good model resolution in the central areas of the model, where we have a number of rays crossing with high ray coverage and relatively small velocity uncertainty (Fig. 7). These tests show that our inversion cannot constrain velocity variations at depths greater than $8.75 \mathrm{~km}$ below the seafloor (bsl) (Fig. 6); thus we limit our interpretation of the velocity model to structure above that level.

Six vertical slices (Fig. 7) are selected across the 3D model, both along and across the Zhenbei and Huangyan seamounts chain located in Fig. 2. The plan view slices (Fig. 8) are focused on the variations with the depth beneath the Zhenbei-Huangyan seamounts chain, at constant depths of 1, 3, 5 and $8 \mathrm{~km}$ bsf. The velocity model from tomographic inversion is our primary result, from which the velocity gradient, velocity anomaly and velocity uncertainty models were derived and used to describe the variations of the velocity structure (Figs. 7, 8). Velocity gradients are useful to characterize seismic layers (Tong et al., 2003). Velocity anomalies are derived by subtracting the average 1D ensemble (Fig. 5) from the final average ensemble for each node of the velocity model. Velocity uncertainties are the statistical standard deviation of the 100 valid solutions. As expected, the edges of the model present large uncertainties $(>0.3 \mathrm{~km} / \mathrm{s})$ due to a decreased number of crossing rays in these areas. The central part of the preferred 3D model is well constrained, with a standard deviation of velocities $<0.2 \mathrm{~km} / \mathrm{s}$ (Fig. 7), smaller than the variance of the initial models used in the Monte Carlo approach (Fig. 5).

\subsection{Tomographic Velocity Model Description}

We use the velocity, velocity gradient, and velocity anomaly models to propose a subdivision of the oceanic crust into layers although there is no interface information in our tomography model. The upper crust (Layer 2), and lower crust (Layer 3) are defined based on the significant change in velocity gradient at the boundary between these two seismic layers. The 6.4 $\mathrm{km} / \mathrm{s}$ iso-velocity contour, corresponding to the sharpest change in velocity gradient, generally coincides with the boundary between layers 2 and 3 (e.g., Muller et al., 1997; Minshull and White, 1996). We tentatively identify the $7.0 \mathrm{~km} / \mathrm{s}$ iso-velocity contour of our tomography model as the 
bottom of Layer 3. We combine velocity and velocity gradient together to differentiate Layer 2 (velocity: $\sim 2.5-5.5 \mathrm{~km} / \mathrm{s}$ and velocity gradients $>1-2 \mathrm{~s}^{-1}$ ) from Layer 3 (velocity: $\sim 6.0-7.0 \mathrm{~km} / \mathrm{s}$ and velocity gradients $<1 \mathrm{~s}^{-1}$ ) (e.g., Harding et al., 1993). The larger dataset and wider azimuthal coverage used here allows for a better characterization of the Zhenbei-Huangyan seamounts chain, in particular for their spatial variations.

Based on the velocity and velocity gradient (Fig. 7), we can distinguish the domain of normal crust from the domain of abnormal crust altered by post-spreading magmatism. Crustal velocities are close to those of normal oceanic crust (Sections $Y=22 \mathrm{~km}, Y=-22 \mathrm{~km}$ and $X=0 \mathrm{~km}$ in Fig. 7) outside post-spreading magmatic intrusions. Perpendicularly to the Zhenbei and Huangyan seamounts chain $(X=0 \mathrm{~km}$ in Fig. 7), the thickness of oceanic Layer 2 is almost 3.0-4.0 $\mathrm{km}$, with a velocity of 3.5-6.4 km/s and a velocity gradient of $>1.0 / \mathrm{s}$; velocities typical of oceanic Layer $3(6.0-7.0 \mathrm{~km} / \mathrm{s})$ are present in the 2.0-3.0 km beneath Layer 2 .

Across seamounts $(X=-40 \mathrm{~km}, X=30 \mathrm{~km}$ and $Y=0 \mathrm{~km}$ in Fig. 7), the crustal structure beneath seamounts is extremely different from other areas, where oceanic Layer 3 shows strong variations in thickness from $2.0 \mathrm{~km}$ to $4.0-7.0 \mathrm{~km}$. The $7.0 \mathrm{~km} / \mathrm{s}$ contour beneath the Zhenbei and Huangyan seamounts can reach a depth larger than $14 \mathrm{~km}$. The high velocity bodies of 7.0-7.4 $\mathrm{km} / \mathrm{s}$ are located just beneath the seamounts (Figs. 7, 8) underlying the roots of seamounts. From the slices at the different constant depths (Fig. 8), the low velocities beneath the seamounts (velocity anomaly in Figs. 7,8 ) indicate that the seamounts display roots even reaching $8.75 \mathrm{~km}$ below the seafloor with a good resolution (Fig. 6) and a small velocity uncertainty $(<0.1 \mathrm{~km} / \mathrm{s})$ (Fig. 7).

\section{Discussion}

\subsection{Nature of the seamounts}

The Zhenbei-Huangyan seamounts chain is a unique feature in the East sub-basin. Outside of the Zhenbei-Huangyan seamounts chain, 1D velocity-depth profiles (Fig. 9) from $X=0 \mathrm{~km}$ section present characteristics of typical oceanic crust (White et al., 1992) with crustal thickness of 4-7 km. 1D velocity-depth profiles beneath the Zhenbei and Huangyan seamounts show an extremely thickened oceanic crust with consistently slow velocities (Fig. 9) compared to typical oceanic crust. The crustal thickness beneath the Zhenbei and Huangyan seamounts is up to $12-14 \mathrm{~km}$ at 
maximum, assuming the $7.0 \mathrm{~km} / \mathrm{s}$ velocity contour as the bottom of crust (Fig. 7).

3D modeling results give the velocity structure in the area of the Zhenbei-Huangyan seamounts chain, which could be used to discriminate between extrusion and intrusive materials due to differences in porosity and fracturation (Hammer et al., 1994). The $6.4 \mathrm{~km} / \mathrm{s}$ iso-velocity contour, acting as the boundary between layers 2 and 3 (e.g., Muller et al., 1997; Minshull and White, 1996), is closely related to the ratio between magmatic intrusion and extrusion (Contreras-Reyes et al., 2010).

Our 3D models show that the upper 1-km of seamounts (Figs. 7, 8) is characterized by low velocities of $1.6-2.5 \mathrm{~km} / \mathrm{s}$, which are indicative of the presence of highly porous clastic material or pillow lavas. We suggest that extrusive basalts are distributed in the upper part of the seamounts, which is consistent with the lithology of dredged samples (Wang et al., 2009). However, the shape of the $6.4 \mathrm{~km} / \mathrm{s}$ iso-velocity contour is still convex upward beneath the Zhenbei and Huangyan seamounts (sections $Y=0 \mathrm{~km}, X=-40 \mathrm{~km}$ and $X=30 \mathrm{~km}$ in Fig. 7). This suggests that the cores of Zhenbei and Huangyan seamounts appear to be dominantly intrusive with velocities faster than 6.4 $\mathrm{km} / \mathrm{s}$. The over-thickened oceanic crust of the seamounts is mainly due to the thickening of Layer 3, with the velocities comprised between 6.0 and $7.0 \mathrm{~km} / \mathrm{s}$ and a velocity anomaly $<1 \mathrm{~s}^{-1}$ immediately beneath the seamounts (section $\mathrm{Y}=0 \mathrm{~km}$ in Fig. 7). Based on the 3D velocity models (Figs. 7, 8) and the 1D velocity-depth profiles (Fig. 9), the velocity structures of the Zhenbei and Huangyan seamounts are similar to those of Ascension Island (Evangelidis et al., 2004) and of the Louisville seamounts (Contreras-Reyes et al., 2010), which are dominantly intrusive, and distinct from Hawaii (Watts et al., 1985) and La Réunion (Charvis et al., 1999), where underplating are mainly associated with a hotspot origin. Therefore, we might infer that the magmatism beneath the Zhenbei and Huangyan seamounts is dominantly formed by intra-crustal intrusion.

The portions of seamounts located in the uppermost mantle and corresponding to velocities between 7.0 and $7.4 \mathrm{~km} / \mathrm{s}$ (Figs. 7, 8) correspond either to mantle underplating or to intra-crustal intrusion. We cannot discriminate between crustal intrusive and upper mantle underplating because the Moho interface is not constrained in our tomographic models. A tomo2d software (Korenaga et al., 2000) approach might constrain this problem. 


\subsection{Formation mechanism of the Zhenbei and Huangyan seamounts chain}

Why did so many seamounts develop in the SCS? And why did volcanism of the Zhenbei-Huangyan seamounts chain continue to be active along a roughly EW-trending feature? Comparing with other examples in the world, e.g. Labrador Sea, the present heat flow of the SCS is exceptionally high, such as $94 \mathrm{~mW} \cdot \mathrm{m}^{-2}$ in the East sub-basin (Shi et al., 2003). The potential contributions to the high heat flow might come from young magmatism (Nissen et al., 1995), emplaced within a recently formed oceanic crust. Previous research on thermal evolution processes of the East (Lin et al., 2013) and Southwest sub-basins (Meng and Zhang, 2014) shows that the buoyancy-driven decompression upwelling mechanism (Castillo et al., 2010) plays an important role in melting processes. The hypothesis of hotspot origin is not supported since the Zhenbei-Huangyan seamounts chain does not show obviously linear variation with age along its trend (Xu et al., 2012). After the cessation of seafloor spreading, the previously trapped mantle melting magma present during the preceding spreading phase was still close to its solidus temperature. Additional buoyancy would then be produced since its density is smaller than that of the surrounding cold mantle. Thus, the buoyancy may continue to drive the mantle upwelling and decompression melting. Products resulting from the decompression meltingin the mantle then ascend and outflow onto the seafloor to form the Zhenbei-Huangyan seamounts chain through pre-existing zones of weaknesses, e.g., previous fractures or faults (Li et al., 2011; Yan et al., 2008). Dredged samples from the Zhenbei and Huangyan seamounts are OIB-type basalt and trachyte, dated 7.4-9.9 Ma (Wang et al., 2009; Yan et al., 2008), showing that magmatic activity in the East sub-basin was very active ca. $10 \mathrm{Ma}$ after seafloor spreading stopped. Different lithologies of OIB-type basalt from the Zhenbei seamount and trachyte from Huangyan seamount (Wang et al., 2009) imply that these two seamounts might be formed from the same magma source but with distinct degrees of partial melting (Meng and Zhang, 2014). From slices at the constant depths (Fig. 8), both seamounts have their own large roots, reaching at least $8 \mathrm{~km}$ below the seafloor (at $\mathrm{Z}=8 \mathrm{~km}$ bsf in Fig. 8). We suggest in Figure 10that the Zhenbei and Huangyan seamounts are derived from the same mantle source but involving with different degrees of partial melting.

The trends of seamounts are also different when we compare the shapes of velocities and velocity anomalies iso-contours at different constant depths (Fig. 8) with the bathymetry (Fig. 2). 
Though the velocity curves (Fig. 8) are largely smoothed with respect to the surface topography, it seems that the mean trends of the seamounts rather follow $\mathrm{N} 055^{\circ}$ trends clearly identified in the surface topography (Sibuet et al., 2015 revised). It suggests that the formation of seamounts was controlled both by tectonic and magmatic processes. During the last stage of seafloor spreading opening, two sets of features ( $\mathrm{N} 055^{\circ}$ trending seafloor spreading lineaments and $\mathrm{N} 145^{\circ}$ trending transform faults) were active in the East sub-basin (Fig. 1) (Sibuet et al., 2015 revised; Li et al., 2002). These features became inactive when seafloor spreading ceased. However, post-spreading magmatism occurred first along these two types of pre-existing zones of weaknesses. In a first stage, magmatism ascended along the recently inactive ESR and associated potential transform faults providing channels for magma migration and eruption along these crustal weak zones. In the eastern part of the East sub-basin, the post-spreading volcanics only develop along the N055 former ESR. It is only during a second stage that the magmatism emplaced along a roughly E-W pattern globally outlined by the direction of the Zhenbei and Huangyan seamounts chain (Fig. 7). Sibuet et al. (2015 revised) have demonstrated that the post-spreading phase of magmatism resulted from a N-S phase of extension evidenced not only by the E-W direction of the Zhenbei and Huangyan seamounts chain but also by the existence of two N-S trending lines of seamounts which mostly developed east of the Southwest sub-basin, in the most recent part of the SCS.

\section{Conclusions}

3D tomographic inversion using first arrivals yielded spatial variations in velocity and thickness beneath the western part of the PSVR, centered on the Zhenbei-Huangyan seamounts chain and across the ESR of the East sub-basin.

The crustal thickness varies obviously due to post-spreading magmatic activities. The crust is of oceanic origin and its thickness is normal, 6-7 km near the ESR and north of the PSVR while beneath the Zhenbei-Huangyan seamounts chain, a maximum thickness of about $14 \mathrm{~km}$ was found, assuming the shape of the $7.0 \mathrm{~km} / \mathrm{s}$ iso-velocity contour as the bottom of crust. Layer 2 , characterized by a strong velocity gradient remains relatively constant in thickness and belongs to volcanic extrusions below the PSVR. Layer 3, characterized by a low velocity gradient, presents major changes between the normal oceanic crust and the crust below seamounts. Based on the ratio of extrusion over intrusive materials and the upward convex shape of the $6.4 \mathrm{~km} / \mathrm{s}$ isocontour 
lines beneath the Zhenbei and Huangyan seamounts, we conclude that the Zhenbei and Huangyan seamounts appear to be dominantly formed of intra-crustal intrusions.

Post-spreading volcanism and seamounts formation were controlled both by tectonic and magmatism. Dredged samples from the Zhenbei and Huangyan seamounts are OIB-type basalt and trachyte, dated as 7.4-9.9 Ma (Wang et al., 2009; Yan et al., 2008), showing that the magmatic activity in the East sub-basin was mostly active ca. 10 Ma after seafloor spreading ceased. The ESR and transform faults acting as tectonic weak zones, provide channels for magma migration and eruption. The Zhenbei-Huangyan seamounts chain does not show obviously linear variation with age, but initially develop along tectonic weak zones and then along an E-W direction, which is orthogonal to the N-S extension responsible for the whole magmatic phase starting $13 \mathrm{Ma}$ and continuing until 3.5 Ma, eventually until now. The formation mechanism of the seamounts chain might be explained by a buoyancy-driven decompression melting mechanism.

\section{Acknowledgements}

We would like to thank the crew of the $R / V$ Shiyan 2 and all scientists, engineers and technicians who participated and were involved in the 2011 cruise. Generous support of OBS instruments were from IGGCAS and SIOSOA. Insightful discussions with Dr. Yongiian Yao and Dr. Hongfeng Yang are kindly acknowledged. The GMT software (Wessel and Smith, 1995) was used in this study. This study is financially supported by the Chinese National Natural Science Foundation (contracts 91028002, 91428204, 41176053) and DY115 (contract DYXM-115-02-1-01).

\section{References}

1. Barckhausen, U., Engels, M., Franke, D., Ladage, S., Pubellier, M. 2014. Evolution of the South China Sea: Revised ages for breakup and seafloor spreading. Marine and Petroleum Geology58, 599-611. http://dx.doi.org/10.1016/j.marpetgeo.2014.02.022.

2. Briais, A., Patriat, P., Tapponnier, P. 1993. Updated interpretation of magnetic anomalies and seafloor spreading stages in the South China Sea: Implications for the Tertiary tectonics of Southeast Asia. Journal of Geophysical Research98(B4), 6299-6328.

3. Castillo, P.R., Clague, D.A., Davis, A.S., Lonsdale, P.F. 2010. Petrogenesis of Davidson 
Seamount lavas and its implications for fossil spreading center and intraplate magmatism in the eastern Pacific. Geochemistry, Geophysics, Geosystems11(2). Q02005, DOI: 10.1029/2009GC002992.

4. Charvis, P., Laesanpura, A., Gallart, J., Him, A., Lépine, J.C., Voogd, B.D., Minshull, T.A., Hello, Y., Pontoise, B. 1999. Spatial distribution of hotspot material added to the lithosphere under La Réunion, from wide - angle seismic data. Journal of Geophysical Research104(B2), 2875-2893.

5. Contreras-Reyes, E., Grevemeyer, I., Watts, A.B., Planert, L., Flueh, E.R., Peirce, C. 2010. Crustal intrusion beneath the Louisville hotspot track. Earth and Planetary Science Letters289(3), 323-333. DOI: 10.1016/j.eps1.2009.11.020.

6. Evangelidis, C.P., Minshull, T.A., Henstock, T.J. 2004. Three-dimensional crustal structure of Ascension Island from active source seismic tomography. Geophysical Journal International159(1), 311-325. DOI: 10.1111/j.1365-246X.2004.02396.x.

7. Expedition 349 Scientists. 2014. South China Sea tectonics: opening of the South China Sea and its implications for Southeast Asian tectonics, climates, and deep mantle process since the late Mesozoic. International Ocean Discovery Program Preliminary Report, 349 http://dx.doi.org/10.14379/iodp.pr.349.2014.

8. Hammer, P.T.C., Dorman, L.R.M., Hildebrand, J.A., Cornuelle, B.D. 1994. Jasper Seamount structure: Seafloor seismic refraction tomography. Journal of Geophysical Research99(B4), 6731-6752.

9. Harding, A.J., Kent, G.M., Orcutt, J. 1993. A multichannel seismic investigation of upper crustal structure at $9^{\circ} \mathrm{N}$ on the East Pacific Rise: Implications for crustal accretion. Journal of Geophysical Research98(B8), 13925-13944. DOI: 10.1029/93JB0886.

10. Klingelhofer, F., Minshull, T.A., Blackman, D.K., Harben, P., Childers, V. 2001. Crustal structure of Ascension Island from wide-angle seismic data: implication for the formation of near-ridge volcanic islands. Earth and Planetary Science Letters190(1), 41-56.

11. Korenaga, J., Holbrook, W.S., Kent, G.M., Kelemen, P.B., Detrick, R.S., Larsen, H.C., Hopper, J.R., Dahl-Jensen, T. 2000. Crustal structure of the southeast Greenland margin from joint refraction and reflection seismic tomography. Journal of Geophysical Research105(B9), 21591-21614. DOI: 10.1029/2000JB900188. 
12. Li, C.F., Li, J.B., Ding, W.W., Franke, D., Yao, Y.J., Shi, H.S., Pang, X., Cao, Y., Lin, J., Kulhanek, D.K., Walliams, T., Bao, R., Briais, A., Brown, E.A., Chen, Y.F., Clift, P.D., Colwell, F.S., Dadd, K.A., Hernández - Almeida, I., Huang, X.L., Hyun, S.M., Jiang, T., Koppers, A.A.P., Li, Q.Y., Liu, C.L., Liu, Q.S., Liu, Z.F., Nagai, R.H., Peleo - Alampay, A., Su, X., Sun, Z., Tejada, M.L.G., Trinh, H.S., Yeh, Y.C., Zhang, C.L., Zhang, F., Zhang, G.L., Zhao, X.X. 2015. Seismic stratigraphy of the central South China Sea basin and implications for neotectonics. Journal of Geophysical Research120(3), 1377-1399. DOI: 10.1002/2014JB011686.

13. Li, C.F., Xu, X., Lin, J., Sun, Z., Zhu, J., Yao, Y.J., Zhao, X.X., Liu, Q.S., Kulhanek, D.K., Wang, J., Song, T.R., Zhao, J.F., Qiu, N., Guan, Y.X., Zhou, Z.Y., Williams, T., Bao, R., Briais, A., Brown, E.A., Chen, Y.F., Clift, P.D., Colwell, F.S., Dadd, K.A., Ding, W.W., Almeida, I.H., Huang, X.L., Hyun, S.M., Jiang, T., Koppers, A.A.P., Li, Q.Y., Liu, C.L., Liu, Z.F., Nagai, R.H., Peleo - Alampay, A., Su, X., Tejada, M.L.G., Trinh, H.S., Yeh, Y.C., Zhang, C.L., Zhang, F., Zhang, G.L. 2014. Ages and magnetic structures of the South China Sea constrained by deep tow magnetic surveys and IODP Expedition 349. Geochemistry, Geophysics, Geosystems15(12), 4958-4983.DOI:10.1002/2014GC005567.

14. Li, J.B., Ding, W.W., Gao, J.Y., Wu, Z.Y., Zhang, J. 2011. Cenozoic evolution model of the sea-floor spreading in South China Sea: new constraints from high resolution geophysical data. Chinese Journal of Geophysics54(6), 3004-3015.

15. Li, J.B., Jin, X.L., Gao, J.Y. 2002. Morpho-tectonic study on late-stage spreading of the Eastern of South China Sea. Science in China (Series D)45(11), 978-989.

16. Lin, W., Zhang, J., Li, J.B. 2013. The thermal simulation of magma activities of the seamount chain after the spreading period. Marine Sciences37(4), 81-87 (in Chinese with English abstract).

17. Minshull, T.A., White, R.S. 1996. Thin crust on the flanks of the slow-spreading Southwest Indian Ridge. Geophysical Journal International125(1), 139-148. DOI: 10.1111/j.1356-246X.1996.tb06541.x.

18. Muller, M.R., Robinson, C.J., Minshull, T.A., White, R.S., Bickle, M.J. 1997. Thin crust beneath ocean drilling program borehole $735 \mathrm{~B}$ at the Southwest Indian Ridge?, Earth Planetary Science Letters148(1), 93-107. DOI: 10.1016/S0012-821X(97)00030-7. 
19. Meng, L., Zhang, J. 2014. The magmatic activity mechanism of the fossil spreading center in the Southwest sub-basin, South China Sea. Science in China (Series D)44(2), 239-249. DOI: 10.1007/s11430-013-4788-x.

20. Nissen, S.S., Hayes, D.E., Buhl, P., Diebold, J., Yao, B.C., Zeng, W.J., Chen, Y.Q. 1995. Deep penetration seismic soundings across the northern margin of the South China Sea. Journal of Geophysical Research100(B11), 22407-22433. DOI: 10.1029/95JB01866.

21. Qiu, X.L., Zhao, M.H., Xu, H.L., Li, J.B., Ruan, A.G., Hao, T.Y., You, Q.Y. 2012. Important processes of deep seismic surveys in the South China Sea: Retrospection and expectation. Journal of Tropical Oceanography31(3), 1-8 (in Chinese with English abstract).

22. Shi, X.B., Qiu, X.L., Xia, K.Y., Zhou, D. 2003. Characteristics of surface heat flow in the South China Sea. Journal of Asian Earth Sciences22(3), 265-277. DOI: 10.1016/S1367-9120(03)00059-2.

23. Sibuet, J.C., Yeh, Y.C., Lee, C.S. 2015 revised. Geodynamics of the South China Sea. Tectonophysics.

24. Taylor, B., Hayes, D.E. 1980. The tectonic evolution of the South China Basin. In: Hayes, D.E. (ed.), The Tectonic and Geologic Evolution of Southeast Asian Seas and Islands. Geophysical Monograph23, AGU, Washington, D.C., 89-104.

25. Taylor, B., Hayes, D.E. 1983. Origin and history of the South China Sea basin. In: Hayes, D.E. (ed.), The Tectonic and Geologic Evolution of Southeast Asian Seas and Islands: Part 2. Geophysical Monograph27, AGU, Washington, D.C., 23-56.

26. Tong, C.H., Barton, P.J., White, R.S., Sinha, M.C., Singh, S.C., Pye ,J.W., Hobbs, R.W., Bazin, S., Harding, A.J., Kent, G.M., Orcutt, J.A. 2003. Influence of enhanced melt supply on upper crustal structure at a mid-ocean ridge discontinuity: A three dimensional seismic tomographic study of $9^{\circ} \mathrm{N}$ East Pacific Rise.Journal of Geophysical Research108(B10).DOI: 10.1029/2002JB002163.

27. Tu, K., Flower, M.F.J., Carlson, R.W., Xie, G.H., Chen, C.Y., Zhang, M. 1992. Magmatism in the South China Basin: 1. Isotopic and trace-element evidence for an endogenous Dupal mantle component. Chemical Geology97(1), 47-63. DOI: 10.1016/0009-2541(92)90135-R.

28. Wang, J., Zhao, M.H., He, E.Y., Zhang, J.Z., Qiu, X.L. 2014. The selection of optimal 
parameters for first-arrival seismic tomography: An application to 3D seismic data from the central sub-basin of the South China Sea. Journal of Tropical Oceanography33(5), 74-83 (in Chinese with English abstract).

29. Wang, X.J., Wu, M.Q., Liang, D.H., Yin, A.W. 1984. Some geochemical characteristics of basalts from the South China Sea. Geochemica4, 332-340 (in Chinese with English abstract).

30. Wang, Y.J., Han, X.Q., Luo, Z.H., Qiu, Y.Z., Ding, W.W., Li, J.B., Gao, S.T., Chen, R.H. 2009. Late Miocene magmatism and evolution of Zhenbei-Huangyan Seamount in the South China Sea: evidence from petrochemistry and chronology. Acta Oceanolgica sinica31(4), 93-102 (in Chinese with English abstract).

31. Watts, A.B, Ten, Brink, U.S., Buhl, P., Brocher, T.M. 1985. A multichannel seismic study of lithospheric flexure across the Hawaiian-Emperor seamount chain. Nature315(6015): 105-111. DOI: $10.1038 / 315105 \mathrm{a} 0$

32. Wessel, P., Smith, W.H. 1995. New version of Generic Mapping Tools released. Eos Transactions American Geophysical Union76(29), 329.

33. White, R.S., Mckenzie, D., O'nions, R.K. 1992. Oceanic crustal thickness from seismic measurements and rare earth element inversions. Journal of Geophysical Research97(B13), $19683-19715$.

34. Wilson, J.T. 1963. A possible origin of the Hawaiian Islands. Canadian. Journal of Physics41(6), 863-870.

35. Xu, Y.G., Wei, J.X., Qiu, H.N., Zhang, H.H., Huang, X.L. 2012. Opening and evolution of the South China Sea constrained by studies on volcanic rocks: Preliminary results and a research design. Chinese Science Bulletin57(24), 3150-3164.

36. Yao, B.C. 1996. Tectonic evolution of the South China Sea in Cenozoic. Marine Geology \& Quaternary Geology16(2), 1-13 (in Chinese with English abstract).

37. Yan, P., Deng, H., Liu, H.L., Zhang, Z.R., Jiang, Y.K. 2006. The temporal and spatial distribution of volcanism in the South China Sea region. Journal of Asian Earth Sciences27(5), $647-659$.

38. Yan, P., Wang, Y.L., Liu, H.L. 2008. Post-spreading transpressive faults in the South China Sea Basin. Tectonophysics450(1), 70-78.

39. Zelt, C.A. 1998. Lateral velocity resolution from three-dimensional seismic refraction data. 
Geophysical Journal International135(3), 1101-1112.

40. Zelt, C.A., Forsyth, D.A. 1994. Modeling wide - angle seismic data for crustal structure: Southeastern Grenville Province. Journal of Geophysical Research99(B6), 11687-11704.

41. Zelt, C.A., Barton, P.J. 1998. Three-dimensional seismic refraction tomography: A comparison of two methods applied to data from the Faeroe Basin. Journal of Geophysical Research103(B4), 7187-7210.

42. Zhang, J., Ten, Brink, U.S., Toksöz, M.N. 1998. Nonlinear refraction and reflection travel time tomography. Journal of Geophysical Research103(B12): 29743-29757.

43. Zhang, L., Zhao, M.H., Wang, J., He, E.Y., Ao, W., Qiu, X.L., Xu, H.L., Wei, X.D., Zhang, J.Z. 2013. Correction of OBS position and recent advances of 3D seismic exploration in the central sub-basin of South China Sea. Earth Science-Journal of China University of Geosciences38(1), 33-42 (in Chinese with English abstract). 


\section{Figures Captions:}

Fig. 1. Bathymetric map and shaded-relief image of the East and Southwest sub-basins of the South China Sea with 200, 1000 and 3000-m isobaths (ESB and SWSB respectively). The red broken lines are the boundaries of the oceanic domain formed during the last spreading phase characterized by $\mathrm{N}^{\circ} 55^{\circ}$ rift trends (Sibuet et al., 2015 revised). The solid yellow line represents the extinct spreading ridge (ESR), the dashed yellow lines represent the transform fault located in the Zhongnan faults zone, between the ESB and SWSB and a close to zero offset fracture zone (Sibuet et al., 2015 revised). A ridge jump ( $\mathrm{Li}$ et al. 2014) is underlined by the black arrow between the orange dashed and solid lines. The magnetic anomalies (white thin lines), the deep-tow magnetic survey profile da13 (thin red line) and multichannel seismic profiles SO49-17, 973SCSIO1 and N3 (thin yellow lines) are from Li et al. (2015). Sibuet et al. (2015 revised) have demonstrated that magnetic lineations previously determined between the $\mathrm{N} 055^{\circ}$ bounds (red dashed lines) are inadequate because they do not take into account the rift trends determined from the continuous swath-bathymetric map of the central part of the East sub-basin. The orange line with triangles indicates the Manila Trench and the yellow star marks the location of Huangyan Island. Red dots indicate Sites U1431, U1433, U1434 drilled during the IODP 349 expedition (Expedition 349 Scientists, 2014).

Fig. 2. (a) Swath bathymetric map and OBS seismic survey located in the area of the Zhenbei and Huangyan seamounts chain. The 3500-m bathymetry contour is shown by thin black lines. OBSs numbers in red characters are inside grey circles. Thin white lines represent airgun shooting tracks. Thick white line is the magnetic anomaly $\mathrm{C} 5 \mathrm{Cr}$. Bold numbers (\#1900 and \#2100) indicate shot numbers at the beginning and end of profiles displayed in Fig. 3. The red star is the location of Site U1431. Red dots show the locations of dredged samples (Wang et al., 1984; Wang et al., 2009). The extinct spreading center (ESR, thick yellow line), the northern boundary of the $\mathrm{N} 055^{\circ} \mathrm{rift}$ trends (thick red dashed line) and the close-to-zero offset fracture zone (thick yellow dashed line) are from Sibuet et al. (2015 revised). (b) Swath bathymetric map of the study area in Cartesian coordinates (origin of the local coordinate system corresponds to $116.91243^{\circ} \mathrm{E}, 15.12553^{\circ} \mathrm{N}$; Y-axis is oriented 3.6 degrees clockwise from North). Six sections in Fig. 7 are marked in black lines in (b). Other features as in (a).

Fig. 3. Examples of two seismic record sections from instruments OBS05(a) and OBS14(b) showing the shooting line recordings (shot \#1900-\#2100 in Fig.2) with the reduced velocity of $6.0 \mathrm{~km} / \mathrm{s}$. OBS14 is off the shooting line while OBS05 is on the line. Data have been 3-8 Hz band-pass filtered and amplitudes have been scaled according to the displayed range. Lower panels show observed travel-time picks (blue vertical bars with length equal to the assigned travel-time uncertainty) and calculated travel-times (red line) predicted by the final model.

Fig. 4. Histograms of travel-time residuals calculated from (a) the 1D starting model and (c) the final model. (b) and (d) display color maps of travel-time residuals as a 
function of shot number and source, predicted from the 1D starting model before inversion and from the final model, respectively. The vertical axis indicates the OBS numbers and the color scale indicates travel-time residuals for each shot. (e) Travel-time residuals of the preferred velocity model as a function of the source-receiver offset.

Fig. 5. (a) 100 Monte Carlo ensembles (blue lines) and ensemble mean (red line). (b) Corresponding standard deviation for the 100 starting models.

Fig. 6. Checkerboard tests. Recovered anomalies are shown for (a) $Y=0 \mathrm{~km}$, (b) $X=0$ $\mathrm{km}$, (c) $Z=5.25$, and (d) $Z=8.75 \mathrm{~km}$ below sea level. Grid lines and yellow $+/-$ symbols show the sinusoidal synthetic velocity anomaly patterns, which are up to $10 \%$ in magnitude relative to the background velocity (mean of the 100 initial ensembles, Fig. 5). Green circles indicate OBSs' positions.

Fig. 7. Six sections $(X=40 \mathrm{~km}, X=30 \mathrm{~km}, X=0 \mathrm{~km}, Y=0 \mathrm{~km}, Y=-22 \mathrm{~km}$ and $Y=22 \mathrm{~km})$ from the 3D final velocity models, velocity gradient, velocity anomaly and velocity uncertainty model (locations are shown in Fig. 2b). Three sections ( $Y=0 \mathrm{~km}, \mathrm{Y}=-22$ $\mathrm{km}$ and $Y=22 \mathrm{~km}$ ) are parallel and three sections ( $X=40 \mathrm{~km}, X=30 \mathrm{~km}$ and $X=0 \mathrm{~km})$ are perpendicular to the Zhenbei and Huangyan seamounts chain, respectively. Masked regions (in white) correspond to lack of ray coverage. Green circles are the positions of OBSs. Velocity contours are shown every $1.0 \mathrm{~km} / \mathrm{s}$. The $6.4 \mathrm{~km} / \mathrm{s}$ and 7.0 $\mathrm{km} / \mathrm{s}$ velocity contours are shown as black bold contours. Four color lines at $\mathrm{Y}=0 \mathrm{~km}$ and $\mathrm{X}=0$ sections are the locations of four 1D models in Fig. 9, respectively. The velocity contours are plotted over the velocity gradient color maps for comparison.

Fig. 8.(a) Four Sections from the final 3D velocity models and (b) Four Sections from velocity anomaly models at constant sub-seafloor depths $(Z=1,3,5,8 \mathrm{~km} \mathrm{bsf})$. The models of velocity anomaly are shown as percentage of variation in final velocity model subtracted from the mean velocity at each depth. Other symbols are as in Fig. 7. Thick black lines are $3500 \mathrm{~m}$ bathymetric contours roughly showing the shape of seamounts.

Fig. 9.(a) 1D velocity-depth profiles beneath OBS23 (green line) and OBS29 (red line) extracted from $Y=0 \mathrm{~km}$ section (locations in Fig. 7)represent the thickened crust below the seamounts summits; 1D velocity-depth profiles beneath OBS03 and OBS06 from $X=0 \mathrm{~km}$ section (locations in Fig. 7) represent the normal oceanic crust. (b) For comparison, 1D velocity profiles from other seamounts, i.e., the Ascension seamount (Klingelhofer et al., 2001) and Louisville (Contreras-Reyes et al., 2010), are dominantly intrusive. The Hawaai (Watts et al., 1985) and La Réunion (Charvis et al., 1999) seamounts are mainly characterized by underplating. Grey-shaded area marks, for reference purposes, velocity range for the 1-127 Ma Atlantic oceanic crust (White et al., 1992). 
Fig. 10. Three dimensional geological model of formation of the Zhenbei-Huangyan seamounts chain based on the $\mathrm{Y}=0$ section abstracted from $3 \mathrm{D}$ velocity anomaly model. The red dashed line is the northern boundary of the $\mathrm{N} 055^{\circ}$ trending seafloor spreading lineamennts of the East sub-basin and the dashed yellow line represents a close to zero offset fracture zone (Sibuet et al., 2015 revised). Magma formed by sustained decompressing melting during mantle upwelling along the tectonic weak zones. The red arrows show the intrusion direction of magma. The intrusive bodies (thin yellow curves) consist of two parts, the upper part is the intrusive core with a velocity of $6.0-6.4 \mathrm{~km} / \mathrm{s}$, and the lower part is composed of gabbroic rocks with sills at the base of the crust with a velocity of $6.4-7.0 \mathrm{~km} / \mathrm{s}$. 
Fig. 1




Fig. 2

Figure 3


Shot Number 
Fig. 4
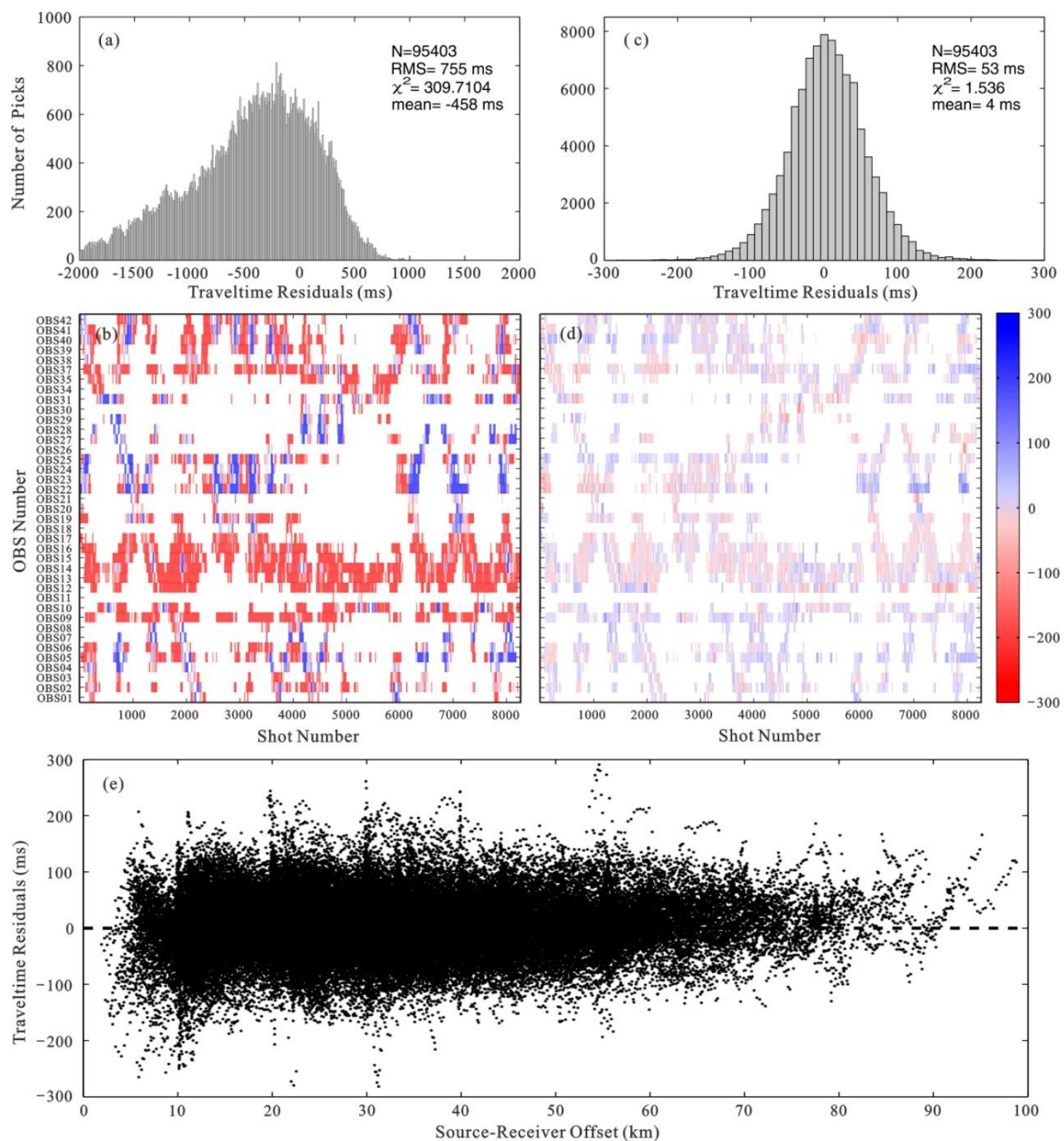
Fig.5




Fig. 6

Fig.7

Fig. 7 continue

Fig. 7 continue




Fig. 8

Fig. 9.

Fig. 10





